\title{
¿Trabajadoras o heroínas? Cuidados sanitarios en tiempos de crisis
}

\author{
Workers or Heroines? Health Care \\ in Times of Crisis
}

\section{Trabalhadoras ou heroínas? A assistência médica em tempos de crise}

Karina Ramacciotti, PhD $^{1 *}$

Daniela Testa, $\mathrm{PhD}^{2}$

Recibido: 28 de octubre de $2020 \cdot$ Aceptado: 25 de marzo de 2021

Doi: https://doi.org/10.12804/revistas.urosario.edu.co/revsalud/a.10598

Para citar este artículo: Ramacciotti K, Testa D. ¿Trabajadoras o heroínas: cuidados sanitarios en tiempos de crisis. Rev Cienc Salud.

2021;19(Especial):1-19. https://doi.org/10.12804/revistas.urosario.edu.co/revsalud/a.10598

\section{Resumen}

Introducción: el artículo reflexiona sobre las tensiones que atraviesan las profesiones vinculadas a los cuidados sanitarios en situaciones de crisis acontecidas en la historia de Argentina. Se consideran tres momentos en los cuales, ante situaciones de crisis políticas, epidemias y catástrofes naturales, las mujeres, en su rol naturalizado de cuidadoras, tuvieron un desempeño más visible. Desarrollo: se analiza la participación de una de las primeras médicas argentinas, Elvira Rawson, durante la Revolución del Parque (26 de julio de 1890, Buenos Aires) cuando, aun siendo estudiante, desafió los criterios establecidos y atendió heridos de bala sin distinguir filiación política. Luego, se reflexiona sobre el papel de un grupo de enfermeras (argentinas y estadounidenses) durante la epidemia de poliomielitis en 1943 y la creación de un controvertido método de rehabilitación ideado por una enfermera, Elizabeth Kenny. Por último, se examina al terremoto sucedido en la provincia de San Juan, en 1944, como un escenario que convocó vocaciones solidarias y estimuló el desarrollo de la enfermería en Argentina. Conclusiones: la retórica de la "vocación”, el "amor al prójimo" o las "dotes naturalizadas otorgadas por el sexo" suelen ser rasgos que se acentúan durante crisis políticas, sociales y sanitarias. La pandemia de covid-19 renueva estrategias discursivas heroicas y sacrificiales que son insuficientes para reconocer los saberes profesionales asociados con las tareas de cuidados, al tiempo que ocultan las malas condiciones de trabajo y las desigualdades sexo-genéricas que se reproducen en el campo sociosanitario.

Palabras clave: cuidados sanitarios; salud; epidemia; desastre; mujer; enfermería; Argentina.

1 Departamento de Ciencias Sociales, Universidad Nacional de Quilmes/Conicet (Argentina). ORCID: https://orcid.org/0000-0002-6724-3926

2 Instituto de Ciencias de la Salud, Universidad Nacional Arturo Jauretche (Argentina). orciD: https:// orcid.org/0000-0003-1293-3775

Autora de correspondencia: karinaramacciotti@gmail.com 


\section{Abstract}

Introduction: This article reflects on the tensions that occurred in healthcare professionals during crisis situations in the history of Argentina. Women, in their naturalized role as caregivers, played a more visible role in the face of political crises, epidemics, and natural disasters. Development: We analyzed the participation of one of the first Argentinean women doctors, Elvira Rawson, during the Revolution of the Park (July 26, 1890, Buenos Aires), when, although she was a student, she defied the establishment by treating gunshot victims, regardless of their political affiliation. We have then highlighted the role of a group of nurses (Argentinean and American) during the polio epidemic in 1943 and a controversial method of rehabilitation developed by Elizabeth Kenny. Finally, we examined the 1944 earthquake that occurred in the province of San Juan as a scenario that called for solidary vocations and stimulated the development of nursing in Argentina. Conclusions: The rhetoric of "vocation," "love of neighbor," or "naturalized gifts given by sex" are features that are often accentuated during political, social, and health crises. The covid-19 pandemic renews heroic and sacrificial discursive strategies that are insufficient to recognize the professional knowledge associated with caregiving tasks, while hiding substandard working conditions and gender inequalities that are reproduced within the social and healthcare fields.

Keywords: Medical care; health; epidemics; disasters; woman; nursing; Argentina.

\section{Resumo}

Introdução: o artigo reflete sobre as tensões que afetam as profissões relacionadas à saúde em situações de crise ocorridas na história da Argentina. São considerados três momentos em que, em situações de crises políticas, epidemias e catástrofes naturais, a mulher, em seu papel naturalizado de cuidadora, teve um papel mais visível. Desenvolvimento: é analisada a participação de uma das primeiras médicas argentinas, Elvira Rawson, durante a Revolução do Parque (26 de julho de 1890, Buenos Aires) quando, ainda como estudante, desafiou os critérios estabelecidos para tratar feridos à bala sem distinguir afiliação política. Em seguida, se reflete sobre o papel de um grupo de enfermeiras (argentinas e norte-americanas) durante a epidemia de pólio em 1943 e o desenvolvimento de um polêmico método de reabilitação idealizado por uma enfermeira, Elizabeth Kenny. Por fim, examina-se o terremoto ocorrido na província de San Juan em 1944, como um cenário que convocou vocações solidárias e estimulou o desenvolvimento da enfermagem na Argentina. Conclusões: a retórica da "vocação", do "amor ao próximo" ou dos "dons naturalizados concedidos pelo sexo" costumam ser traços que se acentuam nas crises políticas, sociais e de saúde. A pandemia covid-19 renova estratégias discursivas heroicas e sacrificiais insuficientes para reconhecer os saberes profissionais associados às tarefas de cuidado, ao mesmo tempo em que oculta as precárias condições de trabalho e as desigualdades de gênero que se reproduzem no campo sociossanitário.

Palavras-chave: cuidados sanitários; saúde; epidemia; desastre; mulher; enfermagem; Argentina.

\section{Introducción}

ـy científicas y nos invita a reflexionar cómo se han modificado las profesiones vinculadas a los cuidados sanitarios en situaciones de crisis acontecidas en la historia de la Argentina. Para ello tomaremos tres momentos en los cuales, ante situaciones de crisis políticas, epi- 
demias y catástrofes naturales las mujeres, en su rol naturalizado de cuidadoras, tuvieron un papel más visible.

Lo que unirá a estos relatos es considerar las labores que ellas realizaron como profesionales ligadas al concepto de cuidado. Dicho concepto se ha asociado, desde las ciencias sociales, a las acciones que las mujeres cumplen en el ámbito doméstico y cómo dicho trabajo, no remunerado, ha permitido la reproducción del sistema capitalista. Se ha vinculado con las actividades de gestión, de limpieza y las tareas de enlace entre los ámbitos doméstico y público, derivadas de las responsabilidades familiares (1). Menos habituales fueron las conceptualizaciones que consideraron la enfermería, el trabajo social, la terapia ocupacional, los apoyos de asistencia domiciliaria y acompañamiento terapéutico y hasta la medicina como prestaciones en las cuales el cuidado es central e indispensable, pero las jerarquías en el interior no son equivalentes y tampoco el prestigio social que a cada una se les asigna. Estas profesiones desempeñan tareas que contribuyen a la salud, la seguridad física y al desarrollo de habilidades cognitivas, físicas o emocionales de las personas (2). Es un cuidado profesional que demanda saberes especializados que requieren una intensa y constante formación no solo hacia el otro y para él, sino hacia su propia sensibilidad, ya que es necesario gestionar las emociones que implican dichas tareas. Todas ellas tienen en común ser prestaciones que se brindan a personas que, de manera transitoria o permanente, necesitan mayores atenciones. Tales atenciones se caracterizan por una inevitable proximidad corporal que suele requerir prolongados tiempos para su realización y, por ende, implican mayor grado de exposición al contagio. Si bien por ser fundamentales para el mantenimiento de la vida este conjunto de tareas es considerado “esencial”, no obstante, cuentan con desigual reconocimiento, prestigio y retribución —entre sí-y en relación con otras.

Desde la historia social y cultural se han estudiado los procesos de salud y enfermedad a lo largo del tiempo y cómo las epidemias y sus consecuencias sociales, demográficas, económicas y políticas propiciaron modificaciones en los sistemas de atención de la salud y en las representaciones y actitudes frente a determinadas corporalidades y situaciones que amenazan la continuidad de la existencia (3,4). Desde la historia de las mujeres, un conjunto de investigaciones ha destacado su rol tanto en la esfera pública como en la privada, y coinciden en señalar que, en el momento de la distribución del trabajo, son ellas las que asumen gran parte de las responsabilidades del bienestar y de la salud de las familias (5-7). Asimismo, otros aportes examinaron los lazos de subordinación y autonomía y estudiaron cómo la dominación sexual patriarcal estructuraba las relaciones y los lugares de trabajo, que trascendía a los escenarios domésticos (8-11).

En particular, la pandemia de la covid-19 ha echado luz sobre las condiciones laborales de las profesiones vinculadas al cuidado sanitario. El pluriempleo, la feminización, los salarios desactualizados, las jornadas de trabajo largas y extenuantes, la carencia de equipos adecuados y las estrategias para afrontar los retos físicos y afectivos no son situaciones nuevas. Por 
el contrario, estas demandas tienen vinculaciones históricas que retomaremos a partir de ciertos episodios en los cuales dichas tareas tomaron mayor visibilización en el entramado mundo de lo sanitario. Por eso, hemos escogido tres momentos en que la feminización de los cuidados tomó mayor relevancia, a partir de crisis políticas, epidémicas y naturales. Lo que une a estas experiencias es que muestran la construcción de relatos heroicos y el lugar de naturalización de las dotes para el cuidado y la asistencia atribuidos a las mujeres; las respuestas que se gestaron a partir de sus saberes, y como "la solidaridad" o, la falta de ella, se acentúan en situaciones de crisis. También evidencian las modificaciones que se generaron para lograr espacios profesionales en los cuales ellas tengan un rol más protagónico, pero sin poner en discusión las desigualdades genéricas ni laborales. Para asomarnos al pasado, utilizamos un conjunto de fuentes que reúne actas y memorias institucionales, prensa, artículos médicos y proyectos legislativos, así como productos culturales actuales (documentales y prensa) que contribuyen a la construcción de una matriz analítica que enlaza presente y pasado y renueva significados sobre los cuidados sanitarios.

\section{Desarrollo}

\section{Elvira Rawson entre cuidados y homenajes}

Elvira Rawson fue la segunda médica egresada de la Facultad de Medicina de la Universidad de Buenos Aires, en 1892. Su tesis para obtener el título de grado fue Apuntes sobre higiene de la mujer. Se casó en 1890 con Manuel Dellepiane con quien tuvo varios hijos. Militante feminista, impulsó el primer centro feminista en defensa de la igualdad de los derechos de las mujeres y participó como organizadora del Primer Congreso Femenino Internacional realizado en Buenos Aires (1910). Su trayectoria se inscribe en la excepcionalidad de la historia universitaria y de las luchas de las primeras mujeres que accedieron a estudios superiores, a pesar de los imaginarios que las consideraban inferiores con respecto a los varones $(12,13)$.

Su primera presencia en el escenario político de la época fue en 1890, cuando asistió a los heridos de balas en la Revolución del Parque del 26 de julio en la ciudad de Buenos Aires. Dicho episodio fue una insurrección armada que, años más tarde, desembocó en la conformación de un importante partido político: la Unión Cívica Radical. Este conflicto se produjo a causa de la oposición de la Unión Cívica de la Juventud ante las medidas tomadas por el presidente Juárez Celman (Partido Autonomista Nacional). Durante su Presidencia se implementaron medidas económicas que convergieron en un proceso inflacionario y que potenciaron conflictos obreros y críticas de los sectores opositores. La Unión Cívica de la Juventud organizó mitines que hicieron de la libertad electoral y el respeto por la Constitución 
Nacional la causa fundamental de su enfrentamiento con el grupo dominante (14). Dicha revolución consistió en un combate civil de cuatro días en el cual participaron entre cinco y seis mil hombres y hubo entre ochocientos y mil muertos o heridos (15). Los sectores rebeldes fueron vencidos, pero el presidente Juárez Celman se vio obligado a renunciar producto de la crisis económica y el desgaste político.

En este contexto, Elvira Rawson, quien por entonces era una estudiante de medicina en la Facultad de Ciencias Médicas de la Universidad de Buenos Aires, se alistó para asistir a los heridos en la contienda. La joven debió solicitar permiso al director del Hospital Rivadavia para brindar servicios en un hospital de campaña instalado entre las calles Lavalle y Talcahuano, epicentro del conflicto. En el llamado Parque de Artillería atendió a quienes lo necesitaron. Elvira no obedeció la orden impartida por las autoridades del hospital de no socorrer a los insurrectos y asistió a los heridos de ambas facciones. La presencia de las mujeres en los espacios públicos, y más en conflictos armados, no era habitual y, menos aún, junto a otros practicantes varones para asistir a otros varones. Si bien, según las ideas de época, se atribuían a las mujeres supuestos saberes naturalizados que las habilitaba para cuidar a otras personas, en los espacios hospitalarios estas tareas quedaban frecuentemente en manos de personal religioso; no era, por entonces, usual que las mujeres intervinieran en las curaciones de primeros auxilios y en los, espacios públicos, solían estar más visibles los varones (6). Los primeros cursos de enfermería (1886) los organizó Cecilia Grierson, quien brindó clases sobre el cuidado de enfermos y primeros auxilios en el Círculo Médico de la Capital. Estos espacios de formación constituyeron el inicio de la Escuela de Enfermeras, Enfermeros y Masajistas de la Ciudad de Buenos Aires (еЕEyм), reconocida como tal en el año 1892, cuando el Estado porteño, a través de la Asistencia Pública, colocó dichos cursos bajo su auspicio (10).

La presencia de Elvira asistiendo a heridos en un escenario de contienda civil no pasó desapercibida por las autoridades de turno. El jefe del hospital de campaña expresó en un parte al general Manuel Campos: "Recomendable es, también, señor general, la conducta de la señorita Rawson, estudiante de medicina, la que en los últimos días, nos acompañó con celo digno de todo aplauso, cuidando con solicitud y contracción a nuestros heridos" (16). El general Campos expresó en su informe: "No debo pasar adelante sin mencionar antes entre las personas que han prestado su consagración a los heridos, a la señorita Rawson, estudiante de medicina, que con su noble ejemplo animaba a los heridos y que allí en ese campo de desolación, era la digna representante de la mujer argentina, siempre pronta a la caridad y al sacrificio" (17).

En estas palabras se destacan las dotes consideradas naturales para una mujer "cuidando con solicitud y contracción”, "caridad y sacrificio”, y en sus concretas tareas profesionales se rescató la de "animar a los heridos". Nada se dijo de sus intervenciones concretas en la asistencia y en la cura, ni su capacidad de resolver situaciones de urgencia. La asignación 
de ciertas atribuciones innatas, por ser “digna representante de la mujer argentina”, oculta el proceso formativo y las trabas que tuvo, en este caso Rawson, para entrar y permanecer en la vida universitaria y sortear las barreras impuestas por el sistema patriarcal.

La “valentía”, la “acción”, la “resolución” de problemas concretos eran aspectos valorizados, dentro de los estereotipos de género, a lo masculino. Por oposición, el sexo “débil” poco podía intervenir en ese sentido. Cuando la realidad irrumpía y contradecía los estereotipos propios del binarismo sexual, se analizaba como excepcionalidad o como aspectos atribuibles a la naturaleza femenina, pero una u otra opción invisibilizan las tareas realizadas por ellas.

Un mes después de la Revolución del Parque, el 1. ${ }^{\circ}$ de septiembre de 1890, en el mitin celebrado en el Teatro Politeama, Rawson pronunció su primer discurso:

Cívicos: La mujer argentina no ha podido acallar en su alma el grito de júbilo y aplauso sincero, que desde un extremo al otro de la República, ha despertado unánime esa legión de patriotas que se llama Unión Cívica. [...] Envuelta en esa oleada de entusiasmo, me ha cabido el honor de ser la intérprete de sus ideas, y no es preciso que diga si orgullosa y complacida acepté la misión [...] Creíamos en el patriotismo, la virilidad y el valor eran recuerdos de otros tiempos que pasaron para nunca más volver, y cuanto más el desaliento nos invadía, habéis venido a probar que sois dignos herederos del sacro nombre que nos legaron nuestros padres. Os habíamos hecho una injusticia, y hoy, complacidas, venimos a devolveros vuestro crédito. ¡Al fin sois argentinos! (18)

Como se desprende de estas palabras, se percibe una construcción del sujeto político masculinizado y subordinado a los “patriotas”. Según Elvira, son ellos quienes siguen contando con la responsabilidad de modificar el orden. El homenaje, asociado a su acción, constituye un espectáculo para ejercer alguna influencia entre las demás personas, pero está alejado de quebrar la gravitación del modelo patriarcal que empezaba a tambalear por las transformaciones iniciadas a partir de la incorporación de las mujeres en la vida universitaria y por los lugares que ocupaban en la escena pública. En este discurso de Rawson no se percibe un posicionamiento crítico respecto al lugar de las mujeres en la sociedad; lo que su práctica política inaugura en los años venideros - en cuanto a una mayor apertura para las mujeres en espacios tradicionalmente masculinizados- no se enuncia en el que es considerado su primer discurso político $(19,20)$.

En dicho evento, Leandro Alem le entregó un reloj de oro y un pergamino en mérito a su labor. Constituye una tradición, a lo largo de la historia, que en los ritos de homenaje se destaquen valores como la abnegación, la entrega, el sacrificio y, en algunos casos, se articulan con la entrega de objetos simbólicos que enmarcan un momento particular para el recuerdo. Tales símbolos pretenden combatir el olvido - individual o colectivo- pero poco dicen de los obstáculos transitados para lograrlos. A la sazón, cuando se exaltan las virtudes por parte de una mujer, en la construcción de sus homenajes se destacan más las dotes supuestamente otorgadas 
por su sexo y cuasi instintivas, que el conjunto de intervenciones profesionales que ellas realizan y su proceso de capacitación.

Con este suceso, queremos destacar algunas de las dificultades que tuvieron las mujeres a fines del siglo xix y principios del siglo xx para intervenir en espacios vinculados con los cuidados sanitarios en espacios públicos. Estos no nacieron feminizados, sino que fue un proceso que condujo a dicha feminización (21). A comienzos del siglo xx, el modelo de enfermería evidenciaba un elevado índice de masculinidad en los hospitales porteños. Recién en 1912, el proceso de feminización se generalizó cuando la веЕум decidió restringir solo a mujeres el ingreso a la carrera (10). Como veremos, a mediados del siglo xx, a tono con lo que sucedió en otras latitudes (22), la presencia de enfermeras en espacios públicos en tareas de prevención y cuidados es parte de los programas formativos; por ejemplo, se impartirán materias específicas para intervenir en casos de "calamidades públicas”. Del mismo modo, los saberes pronunciados desde posiciones feminizadas y subalternas tensionaron el campo sanitario, sobre todo en contextos epidémicos, cuando las respuestas conocidas se tornan insuficientes.

\section{Las "Kenny argentinas" y las lógicas del cuidado en disputa}

A mediados del siglo xx, la poliomielitis estuvo entre las enfermedades que pusieron en jaque la eficacia de la medicina. Se trata de una enfermedad infectocontagiosa que ataca el sistema nervioso central y puede producir secuelas motrices de manera permanente; en casos graves, lleva a la muerte. Hasta la aprobación de la vacuna (en 1955), la incertidumbre acompañó la vida cotidiana en muchas ciudades y enfrentó a los sistemas sanitarios a las frustraciones de lidiar con una enfermedad que no tenía cura. Múltiples debates se forjaron en retóricas heroicas durante las epidemias y se movilizaron recursos de todo tipo - estatales y de la sociedad civil- ante una enfermedad que no distinguía geografías ni sectores sociales (23-25). Esta enfermedad, conocida también como parálisis infantil, alarmaba especialmente porque afectaba en su mayoría a niños. Si bien los índices de mortalidad no eran elevados, la preocupación se centraba en los menores, quienes se sobreponían al virus con deficiencias motoras. El reconocimiento público del problema de la rehabilitación de los “niños lisiados” generó un conjunto de prácticas y discursos que modelaron economías y políticas de cuidado (26).

En 1943, la enfermedad cuadruplicó el número de afectados con respecto al brote del 1936. En dicho contexto, los medios de comunicación propiciaban actitudes de responsabilidad individual y solidaridad social para prevenir el contagio. Los consejos sobre la higiene de los hogares y la alimentación, el cuidado de los niños y el uso de las pastillas de alcanfor conformaban una extensa lista de recomendaciones dirigidas a evitar la diseminación del virus. Las opiniones de los expertos se reproducían para divulgar los avances y los debates 
científicos entremezclados con curas asombrosas y recuperaciones milagrosas. Entre las novedades del momento, concertó gran interés el método ideado por la enfermera australiana Elizabeth Kenny. ${ }^{3}$ Se trataba de un conjunto de procedimientos para aliviar el dolor, así como para evitar contracturas y deformaciones, destinados a evitar la parálisis. El método Kenny lograba que los niños se pusieran de pie y caminaran por sus propios medios. Por ese entonces, narrativas optimistas — sostenidas tanto por expertos como por legos—reflejaban un ideal de recuperación que se alcanzaba con la capacidad de caminar y de acceder al mercado laboral competitivo (27).

Kenny inventó el método en 1911, según su experiencia como enfermera rural en Australia. Fueron sus ideas sobre la naturaleza de la poliomielitis las que suscitaron inflamadas polémicas: si Kenny estaba en lo cierto, la parálisis no era entonces una consecuencia natural e inevitable de la enfermedad, sino un indeseable resultado del tratamiento tradicional de inmovilización de los ortopedistas. La enfermera concebía la enfermedad como una alteración de los músculos y de la piel y señalaba que los espasmos musculares eran consecuencia de la inflamación y del dolor. Dichos espasmos, al ser tratados de forma inapropiada, eran los causantes de la "invalidez" que producía la enfermedad. Esa ruptura tenía varias caras: por un lado, cuestionaba el razonamiento clínico de la biomedicina. Por otro, enunciaba saberes que tensionaban las representaciones de lo que en ese entonces se consideraba científico en el campo. Además, este lugar de confrontación era ejercido desde una posición de subordinación ocupado por la enfermería. Si bien entre los médicos muchos reconocían la eficacia del método, especialmente en cuanto a la reducción del dolor, no avalaban el marco interpretativo de la enfermera. Los hombres de ciencia, si bien respetaban a Kenny por ser una mujer de carácter firme, justa y tesonera, devaluaban sus ideas por considerar sus argumentos como acientíficos y basados exclusivamente en la intuición y la mera práctica. No obstante, aceptaban que contaba con conocimientos sobre la anatomía de los músculos y que, aun sin preparación científica, había impulsado una necesaria renovación de los métodos de tratamiento. Kenny se había convertido en una figura de cierta relevancia pública y su metodología fue aceptada entre los familiares de los enfermos (28-30).

En sintonía con los adelantos en las técnicas de rehabilitación de entreguerras, los médicos especialistas concentrados en el Hospital de Niños de la Ciudad de Buenos Aires se interesaron por el método e impulsaron una experiencia piloto dirigida por el ortopedista Marcelo Fitte. En medio de la epidemia de 1943, a mediados de marzo, llegaron a Buenos Aires dos enfermeras, Mary Steward-Kenny y Ethel Gardner, acompañadas por el médico

Algunos ecos en la prensa pueden verse en: La Razón, "Aplicarían desde mañana método Kenny contra las secuelas de la poliomielitis", 17 de marzo de 1943, p. 5. "Una Comisión médica de los Estados Unidos llegará hoy a Buenos Aires. Aplicarán en nuestro país el método Kenny para la poliomielitis", 16 de marzo de 1943, p. 6. La Nación, "El Método Kenny y el tratamiento de la Parálisis Infantil", 8 de enero de 1943, p. 4. 
Rutherford John, con la finalidad de trasmitir las técnicas (31). La comitiva fue enviada por el gobierno de Estados Unidos y la National Foundation of Infantile Paralysis (FNIP), institución fundada en 1938 por Franklin Delano Roosevelt (quien adquirió esta enfermedad en 1921), con el fin de recaudar fondos para investigar sobre poliomielitis.

El método Kenny era una actividad laboriosa y requería tiempo y atención personalizada. Se utilizaban paños de tela, agua caliente, recipientes, escurridores, toallas y camillas especiales. La tarea consistía en envolver los miembros afectados con franelas de algodón mojadas en agua caliente, escurridas previamente para evitar las quemaduras. Los vendajes se renovaban cada dos horas, pero si los dolores eran muy acentuados, se podían cambiar cada quince minutos (durante un lapso de doce horas si era necesario). Aplicar este tratamiento demandaba, pues, contar con personal de enfermería especializado dispuesto a llevar adelante una pesada jornada que implicaba permanecer de pie largas horas, consolar llantos infantiles, mecer a los pequeños en brazos y tener una atenta mirada sobre la persona atendida (32).

El persistente problema de la escasez de personal sanitario se acentuaba durante las epidemias y, sumado a tendencias que venían desde antes, hicieron casi obvio que ante la necesidad de incrementar el personal extra, se apelara a las mujeres para aplicar las nuevas técnicas. A medida que aumentaban los contagios, se abrían nuevos cargos, siempre de carácter provisorio y extraordinario, sujetos a la evolución epidemiológica. La ecuación concertaba la aptitud y la capacidad de abnegación y sacrificio para el cuidado - esencializados como atributos propios de las mujeres - con bajos sueldos y condiciones laborales precarias. El interés en ocupar ese tipo de cargos públicos puede explicarse con un conjunto de razones que combinan la atracción por obtener un ingreso, aun siendo exiguo, con la desvalorización del propio trabajo basado en la concepción del aporte monetario femenino como complementario al de los varones y en la naturalización de las tareas asumidas (33). Además, como profesión tempranamente feminizada en nuestro país, la enfermería (junto con visitadoras, puericultoras, asistentes de laboratorio, parteras) representaba una profesión “atajo”, una vía de acceso relativamente rápida al empleo en el área de la atención médica (10).

De cara al golpe militar del 4 de junio de 1943, a tres meses de la llegada de la comitiva norteamericana, la FNIP recomendó interrumpir la estadía de las enfermeras en Buenos Aires y dispuso su inmediato regreso a Minneapolis. Similar reacción fue adoptada desde la Fundación Rockefeller, que suspendió los programas de capacitación de enfermeras y otros estímulos a la investigación médica. Finalmente, con el aval y el dinero provisto por Elizabeth Kenny, ya que la fNIP había retirado el financiamiento, las enfermeras permanecieron en Buenos Aires hasta mediados del año, una vez superado el pico epidémico. Las ideas de carácter nacionalista y antinorteamericana de las autoridades entrantes y la política de neutralidad adoptada por la Argentina durante la Segunda Guerra provocaron el alejamiento de las relaciones formales entre Estados Unidos y Argentina. La política internacional se metió de lleno en la política nacional e interrumpió los procesos de implementación de proyectos 
sanitarios, de investigación y de capacitación de recursos humanos auspiciados por instituciones norteamericanas (34). A pesar de la inestabilidad y de las desventajosas condiciones de trabajo, el grupo de enfermeras argentinas capacitadas por las norteamericanas tuvieron un rol destacado durante la epidemia de 1943. Estas mujeres - las Kenny argentinas-, por su experticia, realizaron viajes de perfeccionamiento y brindaron capacitaciones en diferentes ciudades argentinas, en Chile y en Uruguay, y fueron quienes, a través de su ejercicio profesional, validaron el método en el país (32).

Una vez superada la epidemia, y con el fin de apreciar mejor los resultados de esta técnica, el equipo de especialistas del Hospital del Niños continuó con las actividades de investigación, a efectos de capitalizar los aprendizajes invertidos y asistir a los enfermos de otras epidemias. Sin embargo, los recursos hospitalarios asignados fueron interrumpidos. Para entonces, la Sociedad de Beneficencia de la Capital (encargada de administrar el Hospital de Niños, entre otras instituciones asistenciales) enfrentaba dificultades financieras para mantener los servicios en condiciones. En ese contexto, financiar las actividades del equipo de poliomielitis, una vez solucionada la epidemia, era un aspecto difícil de sostener. Resulta comprensible la preocupación de los equipos médicos por aquellos niños de escasos recursos para quienes la discontinuidad de un tratamiento adecuado significaba altas probabilidades de padecer deformaciones osteoarticulares y deterioro en su salud. Esta situación no pasó inadvertida a las "voluntarias", quienes asumieron un relevante papel durante las epidemias (conseguían medicamentos e insumos, acompañaban a familiares y a enfermos, colectaban fondos). En tales circunstancias, un grupo de ellas - vinculadas a los servicios de poliomielitis-creó, en 1943, la Asociación de Lucha contra la Parálisis Infantil. Constituida por mujeres de sectores medios y altos, algunas conocieron la enfermedad a través de sus familiares y eran conscientes de la importancia de sostener los prolongados y onerosos tratamientos de rehabilitación. Esta organización -en sus inicios subsidiaria de los hospitales públicos-se convirtió en una referencia obligada en rehabilitación motriz y congregó a los especialistas destacados de la época (35).

En otra oportunidad escribimos sobre los "etcétera del cuidado" para señalar el lugar protagónico de las mujeres durante las epidemias. Utilizamos la palabra "etcétera" para acentuar la invisibilización y la falta de reconocimiento de innumerables tareas que fueron desempeñadas por mujeres en contextos epidémicos. Si bien esas tareas, al ser vistas como continuidades del dominio doméstico, resultaron desvalorizadas y mal remuneradas, materializaron (y materializan) dimensiones afectivas y éticas que fueron (y son) fundamentales no solo durante las emergencias, sino porque contribuyen con abordajes que van más allá del uso exclusivo de tecnologías biomédica (36). 


\section{El terremoto de San Juan, el despertar de vocaciones}

Un suceso que ha tenido un rol importante para la promoción de espacios de capacitación en la enfermería en Argentina fue el terremoto de San Juan, de 1944. Este desastre natural ocurrió el 15 de enero y dejó alrededor de diez mil muertos y la mitad de la provincia sin vivienda. El dramatismo del suceso puso en evidencia las carencias sociales y la falta de infraestructura. Como señala Mark Healey:

Es solo la presencia humana, y el derrumbe de las construcciones humanas, lo que convierte los acontecimientos sísmicos en desastres naturales. Más allá de las estructuras físicas, parte de la culpa del desastre puede encontrarse también en las estructuras sociales y en las relaciones de poder que ponen en riesgo a ciertos grupos sociales y no a otros. Si bien estas estructuras sociales suelen ser invisibles o darse por sentadas, un desastre de proporciones puede sacarlas a la luz y someterlas a un cuestionamiento. (37)

Las necesidades sanitarias que se produjeron, el miedo por la potencial infección proveniente del sepulcro abierto y la inminente campaña de vacunación contra el tifus demandaron un enorme operativo médico conformado tanto por argentinos como por chilenos (37). Asimismo, aceleró la puesta en funcionamiento del Hospital Central en Mendoza. Este nosocomio se comenzó a utilizar, por disposición de las autoridades nacionales, antes de finalizar las obras, para albergar a quienes habían sufrido las consecuencias del terremoto de la provincia aledaña (38).

Este suceso fue una experiencia desgarradora para la región y demostró, una vez más, que la Argentina era mucho más de lo que sucedía en Buenos Aires. Juan Domingo Perón, por entonces secretario de Trabajo y Previsión, supo interpretar las posibilidades políticas de dicho momento, y para satisfacer las acuciantes demandas sociales, organizó una campaña solidaria a cargo de la institución estatal que presidía. Con este emprendimiento desplazó a las instancias de caridad privada, que solían tener un rol activo en este tipo de acciones, e inauguró una decidida apuesta por la intervención social bajo instancias estatales y en pos de lograr la concreción de derechos sociales postergados. La colecta y el protagonismo de Perón marcó el inició de su proyecto político, que lo condujo a la Presidencia dos años más tarde (1946).

La Secretaría de Trabajo y Previsión repartió alimentos y medicinas, de forma diaria, a cuarenta y cinco mil sobrevivientes en San Juan y a quince mil refugiados en otros lugares; además, se despacharon toneladas de donaciones vía ferrocarril a San Juan. Los medios de comunicación tuvieron un rol destacado para dar a conocer las necesidades y lograr la sensibilidad social necesaria para fomentar las donaciones (37).

En los desastres naturales o en las situaciones de emergencia se generan momentos de solidaridad, se crean oportunidades laborales y, también, se suelen despertar vocaciones. 
Como sostiene Orhan Pamuk, ante situaciones de catástrofes "el miedo provoca dos respuestas diferentes, en mí y quizá en todos nosotros. A veces me empuja a encerrarme en mí mismo, en la soledad y el silencio. En otras ocasiones, me enseña a ser humilde y practicar la solidaridad" (39). En el terremoto de San Juan, mientras algunos médicos se fugaban en el momento en que eran más necesitados, voluntarios encontraban personas con vida bajo los escombros luego de tres días del evento, tal como el caso de la hija de un terrateniente que se había dado por muerta (40), o muchas mujeres se sintieron atraídas para ocupar puestos de enfermería o para capacitarse luego de las urgencias y demandas sanitarias que quedaron visibilizadas por la prensa periódica, la radio y las colectas públicas de un suceso provincial que tomó ribetes nacionales. Por ejemplo, Margarita Basomba, enfermera egresada de la Cruz Roja porteña y quien tuvo un lugar preponderante en la enfermería de la ciudad de La Plata, señaló que este suceso marcó su vida, ya que fue una de las integrantes de la delegación instalada en Mendoza con el fin de socorrer a heridos que llegaban desde San Juan. Además, presenció la muerte de dos colegas, dado un desperfecto en un avión que se dirigía a dicha provincia. Ambos sucesos trágicos apuntalaron aún más su espíritu solidario y se inclinó definitivamente por esta profesión, que durante los años venideros la tuvo en sitiales de reconocimiento profesional $(41,42)$.

Tal como señalan Adriana Álvarez y María Silvia Di Liscia (43), las escuelas de enfermeras de la Cruz Roja argentina tuvieron una importante expansión luego de los terremotos de Mendoza (1929) y de Salta (1930) y estimularon el interés de mujeres jóvenes por capacitarse en tareas humanitarias para dar respuesta a situaciones de desastres; pero la necesidad de recursos humanos capacitados tomó mayor relevancia nacional luego del sismo de San Juan. Ante esa situación, la Secretaría de Salud Pública (ssp), creada en 1946 durante el Gobierno peronista (1946-1955), impulsó, a tono a lo que estaba sucediendo en otras latitudes, la creación de espacios educativos que profesionalizaran la práctica sanitaria. Para tal fin se impulsó la Escuela de Enfermeras de la ssp en 1947. En este último ámbito, se abrió un espacio de inserción a las mujeres, relacionado con la enfermería, para las que eran consideradas especialmente dotadas en función de las nociones de género de la época. Tres años más tarde, la Fundación Eva Perón fundó la Escuela de Enfermeras 7 de Mayo. Ambas mejoraron la capacitación y brindaron una formación dirigida a la atención de las personas hospitalizadas y a las tareas de prevención en los espacios urbanos y rurales. La Escuela de Enfermeras de la Fundación Eva Perón contaba con una materia para intervenir en casos de catástrofes. El curso de Defensa Nacional y Calamidades Públicas tuvo como objetivo brindar nociones para intervenir en casos de "guerra, sublevaciones y huelgas generales" y también contaban con capacitación para que ellas pudieran manejar vehículos necesarios para la movilidad sanitaria (44).

Estos espacios formativos se constituyeron en una opción laboral para numerosas mujeres que veían en esta profesión una entrada al mercado laboral y también un trabajo que 
no debía soportar el peso del estigma asociado a las obreras. Tal como lo ha señalado Mirta Lobato (6), las trabajadoras fabriles sufrían una doble culpabilización: por ausentarse de su hogar y por exponer su cuerpo a las exigencias del mundo industrial que, según se creía, ponía en riesgo la capacidad reproductiva.

En sendas escuelas se mantuvieron los enunciados vinculados a la vocación de servicio y al espíritu caritativo. La apropiación de ciertas ideas del mundo religioso, trasladadas al espíritu solidario, de ayuda al prójimo, de concreción laica del ideal cristiano, influyó para que muchas personas se sintieran convocadas para esta profesión. Otro aspecto para destacar fue el interés de promover un modelo de enfermería centrado en la detección de necesidades sociales y sanitarias en los lugares carenciados. Las experiencias de trabajo en el barrio porteño de Villa Soldati de las enfermeras de la Escuela de Enfermería de la ssp, en 1947, es un ejemplo de ello. La detección temprana de potenciales enfermedades, la enseñanza de pautas de higiene y cuidado, la administración de vacunas y la derivación, si fuera necesario, a centros asistenciales fueron aspectos que comenzaron a tener mayor protagonismo entre las tareas de la enfermería y se expandieron durante la segunda mitad del siglo xx (45).

Entonces, una catástrofe natural, tal como el desastre que ocasionó el terremoto de San Juan, favoreció la creación de espacios de capacitación que mejoraran las pericias dentro del sector de enfermería. Si bien los argumentos se centraron en las supuestas dotes de sacrificio y cuidado innato que ellas portaban por su sexo, el proceso marcó un mojón dentro de la historia de la profesión. Aunque mantuvieron un rol subordinado a las indicaciones de los profesionales de la salud, contaron tanto con saberes para desenvolverse en el espacio hospitalario como con nociones para intervenir en espacios públicos, por ejemplo, barrios carenciados o situaciones de emergencia. Sin lugar a duda, si bien se complejizaron conocimientos y experiencias laborales, esto no devino en una discusión en torno a sus derechos laborales. En efecto, en la medida en que el proceso de feminización reclamaba más mujeres para la enfermería, ellas no recibían un reconocimiento pecuniario ni profesional concomitante pues, precisamente, su demanda se basaba en la idea de que la precarización era consustancial al ejercicio de dicha actividad y que ellas, por sus condiciones naturales, podían sobrellevarla sin conflicto. En la práctica, las organizaciones de enfermeras, que se comenzaron a formar en este periodo, también tuvieron problemas para efectivizar sus demandas, porque incurrían en una lógica semejante. Sin embargo, evidenciaron que en cuanto trabajo, su tarea merecía un salario digno que les permitiera satisfacer sus necesidades básicas y sobre esa lógica tallaron en el espacio público (46). 


\section{Reflexiones finales}

- Cómo se pueden enlazar estas experiencias históricas vinculadas con reconocimientos, relaciones entre las profesiones del cuidado y la política nacional o internacional y el estímulo a instancias de capacitación desde el Estado en torno a tareas ligadas al cuidado con la covid-19? ¿Es posible identificar semejanzas y diferencias entre estas experiencias y nuestros tiempos?

Estamos frente a un contexto plagado de actitudes de cuidados solidarios que logran superar las filiaciones políticas de quienes son sujetos de atenciones. Multiplicidad de agentes de cuidado, día tras día, sin materiales adecuados, con extenuantes jornadas de trabajo, brindan cuidados a quienes deben transitar el coronavirus en un contexto de aislamiento. Son figuras anónimas; en los casos más trágicos se conocen sus nombres cuando fallecen. Sus homenajes simbólicos están desvanecidos. Los aplausos sincronizados que se realizaban en el mes de marzo de 2020, a imitación de lo que sucedía en las capitales europeas, se extinguieron. Un periódico realizó un informe titulado "Los héroes que hemos perdido", en el que se registra la cantidad de médicos, enfermeros y auxiliares contagiados y fallecidos. En el momento de publicación de la nota periodística, octubre de 2020, existían el 5.0\% del total de los contagios y el $0.90 \%$ de las muertes por coronavirus; además, brindaba breves referencias biográficas de quienes "murieron en el frente de batalla, peleando cara a cara con el coronavirus sin bajar los brazos más allá de las condiciones de trabajo que hayan tenido que enfrentar" (47).

Los medios de información masivos pueden referirse a ellos como "héroes y heroínas de la salud", "ejército anónimo de voluntades", "la avanzada", "la primera línea de batalla”, pero sin profundizar sobre sus condiciones laborales, su falta de reconocimiento y de prestigio social. El “amor por la profesión”, la "pasión”, "la ayuda amorosa” sobresalen por sobre las carencias estructurales que portan las profesiones ligadas al cuidado (48).

Estas representaciones sobre el personal de salud convivieron con denuncias de situaciones de discriminación dirigidas hacia el personal de salud por parte de sus vecinos, por ser culpabilizados como vectores de contagio. Asimismo, sus reclamos en torno a la necesidad de respetar las recomendaciones sanitarias para evitar el colapsamiento del sistema de salud no parecieron ser escuchadas, ya que abundaron múltiples actitudes de desobediencia civil, negación de la enfermedad y falta de empatía, que se produjeron día a día con bares repletos de personas, quemas de barbijos, manifestaciones políticas presenciales que, en muchos casos, no guardaban los recaudos aconsejados y articulaciones discursivas contra la vacuna considerada como un medio de control social.

En un horizonte futuro, esperamos que luego de esta pandemia se activen los espacios de capacitación para incrementar la formación en los cuidados sanitarios, pero que dichas instancias traigan un serio debate en torno a sus condiciones laborales, derechos y 
reconocimiento. Las profesiones del cuidado sanitario están marcadas por el pluriempleo, lo que en esta pandemia colaboró a incrementar los casos de contagio, por concurrir a diferentes instituciones para tener un salario digno. Los contratos de trabajo rozan con la ilegalidad, ya que no garantizan derechos laborales adquiridos. Además, se ha denunciado falta de personal capacitado en técnicas de cuidados críticos y la carencia de elementos de protección personal, agotamiento físico, mental y miedo.

La retórica a la "vocación”, el "amor al prójimo" o las "dotes naturalizadas otorgadas por el sexo" ya no alcanzan para reconocer los saberes profesionales que están asociados a estas labores y que constituyen el eslabón clave e indispensable del sistema de salud. En el mundo que estamos atravesando, las enfermedades crónicas, endémicas y epidémicas son una constante en nuestras vidas y nuestras emociones. Por tanto, sin políticas de Estado que apuesten a la capacitación, a la investigación científica y a la salud pública, serán menores las posibilidades de reducir las desigualdades sociales y el impacto que ellas generan.

La celebración de los "Héroes y heroínas de la salud pública”, estrategia política utilizada por las autoridades oficiales cuando pasan las crisis sanitarias por medio de entrega de medallas o relojes, como en el caso de Elvira Rawson, no modifica las condiciones de trabajo y solo colaboran en aumentar el panteón heroico de la historia de la medicina con bronce pero, en muchos casos, sin un debate en torno al reconocimiento, prestigio y mejoras salariales. Retomamos, en este sentido, las palabras de Maximiliano Fiquepron, cuando sostiene:

[...] la aparición de algunas figuras emblemáticas, la forma en que se describen los cuerpos y escenas y el propio ritmo que tiene la narración de la epidemia constituyen elementos que brindan la posibilidad de encauzar un acontecimiento traumático, sobre todo, que enlazan esa experiencia con otras: "normalizan" la crisis al ponerla en comparación con otras semejantes. (49)

Esperamos que la pandemia de la covid-19 signifique la posibilidad de reflexionar sobre este suceso como una inflexión en cómo se modificó el rol de Estado y las condiciones sanitarias y laborales de los agentes del cuidado y, sobre todo, que recordemos como un lejano hecho del pasado los actuales reclamos desesperados del personal de salud.

\section{Contribución de las autoras}

\footnotetext{
A mbas autoras planificaron, analizaron información, buscaron bibliografía y redactaron $\mathrm{I}$ el artículo.
} 


\section{Agradecimientos}

$\mathrm{N}^{\prime}$

uestro agradecimiento hacia Karina Brovelli y Joaquín Fernández Vila, quienes están siempre dispuestos para acompañar y colaborar.

\section{Financiación}

— ste artículo se inscribe dentro de los resultados de los siguientes proyectos El proceso de Lprofesionalización del cuidado sanitario. La enfermería universitaria en Argentina (19401970), de la Universidad Nacional de Quilmes (827-1290/19); el PIP Género y modernización política (Argentina, 1955-1970), de la Universidad Nacional de La Plata, periodo 2019-2021, y el PISAC-COVID-19: La enfermería y los cuidados sanitarios profesionales durante la pandemiay la postpandemia del covID-19 (Argentina, siglos xx y XXI), avalado por la Agencia Nacional de Promoción de la Investigación, el Desarrollo Tecnológico y la Innovación.

\section{Descargos de responsabilidad}

as autoras asumen la responsabilidad de lo publicado y la Revista de Ciencias de la Salud
no asume ninguna responsabilidad por ello.

\section{Conflicto de intereses}

Ninguno declarado.

\section{Referencias}

1. Jelin E. Pan y afectos. Buenos Aires: Fondo de Cultura Económica; 1998.

2. Pereyra F, Micha A. La configuración de las condiciones laborales de la enfermería en el Área Metropolitana de Buenos Aires: un análisis en el cruce del orden de género y la organización del sistema de salud. Salud Colect. 2016;12(2):221-38. https://doi. org/10.18294/sc.2016.730

3. Armus D. El descubrimiento de la enfermedad como problema social. En: Lobato M, director. El progreso: la modernización y sus límites (1880-1916). Vol. 5. Buenos Aires: Sudamericana; 2000. 
4. González Leandri R. Curar, persuadir, gobernar: la construcción histórica de la profesión médica en Buenos Aires, 1852-1886. Madrid: CSIC; 1999.

5. Barrancos D. Mujeres entre la plaza y la casa. Buenos Aires: Sudamericana; 2008.

6. Lobato M. Historias de las trabajadoras en la Argentina (1869-1960). Buenos Aires: Edhasa; 2007.

7. Queirolo G. Mujeres en las oficinas: trabajo, género y clase en el sector administrativo (Buenos Aires, 1919-1950). Buenos Aires: Biblos; 2019.

8. Pozzio M. Análisis de género y estudios sobre profesiones: propuestas y desafíos de un diálogo posible y alentador. Sudamérica. 2012;1:99-129.

9. Biernat C, Cerdá JM, Ramacciotti K. La salud pública y la enfermería en la Argentina. Bernal: Universidad Nacional de Quilmes; 2015.

10. Martín AL. Mujeres y enfermería: una asociación temprana y estable (1886-1940). En: Biernat C, Cerdá JM, Ramacciotti K, directoras. La salud pública y la enfermería en la Argentina. Bernal: Universidad Nacional de Quilmes; 2015. p. 257-86.

11. Gavrila C. Prevenir y persuadir: la radio y las visitadoras de higiene en las décadas de 1930 y 1940 en la ciudad de La Plata. Avances del Cesor. 2016;XIII(15):93-111. https:// doi.org/10.35305/ac.v13i15.630

12. Lorenzo MF. Que sepa coser, que sepa bordar, que sepa abrir la puerta para ir a la universidad: las académicas en la Universidad de Buenos Aires en la primera mitad del siglo XX. Buenos Aires: Eudeba; 2016.

13. Barrancos D. Mujeres en la sociedad argentina: una historia de cinco siglos. Buenos Aires: Sudamericana; 2007.

14. Lobato M. Estado, gobierno y política en régimen conservador. En: Lobato M, dirección. Nueva historia argentina. Buenos Aires: Sudamericana; 2000. p. 179-208.

15. Alonso P. La Unión Cívica Radical: fundación, oposición y triunfo (1890-1916). En: Lobato M, dirección. Nueva historia argentina. Buenos Aires: Sudamericana; 2000. p. 209-60.

16. Gallo R. Las mujeres en el radicalismo argentino 1890-1991. Buenos Aires: Eudeba; 2001.

17. Informe del Gral. Campos sobre accionar de Elvira Rawson. En: Gallo R. Las mujeres en el radicalismo argentino 1890-1991. Buenos Aires: Eudeba; 2001.

18. Primer discurso político de Elvira Rawson. En Gallo R. Las mujeres en el radicalismo argentino 1890-1991. Buenos Aires: Eudeba; 2001.

19. Cammarota A. Elvira Rawson en el Sur, Elvira Rawson contra el Consejo Nacional de Educación (1926). En: Workshop Salud y Educación: una mirada interdisciplinaria. Actores, intervenciones estatales y sociedad civil. Argentina: 1890-2019. San Justo: Universidad Nacional de La Matanza; 2019.

20. Valobra A. Feminismo, sufragismo y mujeres en los partidos políticos en la Argentina en la primera mitad del siglo XX. Amnis. 2008;8. https://doi.org/10.4000/amnis.666

21. Wainerman C, Binstock G. Género y ocupación en el sector de enfermería. Estudios del Trabajo [internet]. 1994;7:44-65. Disponible en: http://catalinawainerman.com.ar/pdf/ El-nacimiento-de-una-ocupaci-femenina-La-nferme.pdf 
22. Queirolo G, Zárate Campos MS, directoras. Camino al ejercicio profesional: trabajo y género en Argentina y Chile (siglos xix y xx). Santiago de Chile: Editorial Alberto Hurtado; 2020.

23. Asociación Lucha contra la Parálisis Infantil. Memorias institucionales, 1943, 1944, 1945. Buenos Aires.

24. Argentina, Cámara de Diputados. Proyecto de Ley "Creando, con asiento en la Capital Federal y dependiente del departamento Nacional de Higiene, la sección Parálisis Infantil”; septiembre 1938.

25. Argentina, Cámara de Diputados. Proyecto de Ley “Creación de la sección Parálisis Infantil bajo la dependencia del Departamento Nacional de Higiene”; junio 1940.

26. Testa D. Del alcanfor a la vacuna Sabin: la polio en la Argentina. Buenos Aires: Biblos; 2018.

27. Rogers N. Polio wars: sister Kenny and the golden age of American medicine. Oxford: University Press Scholarship Online; 2013.

28. Berg R. La lucha contra la poliomielitis. Buenos Aires: Nova; 1949.

29. Una Comisión médica de los Estados Unidos llegará hoy a Buenos Aires: aplicarán en nuestro país el método Kenny para la poliomielitis. La Prensa, 16 de marzo de 1943, p. 7.

30. Llegaron ayer los especialistas norteamericanos en poliomielitis. La Prensa, 17 de marzo de 1943, p. 6.

31. Sociedad de Beneficencia de la Capital. Actas de Consejo: día 23 de diciembre de 1942; 7 de enero de 1943; 23 de marzo de 1943.

32. Sociedad de Beneficencia de la Capital. Legajo 113, expediente 9355 (1942-1944).

33. Ramacciotti K, Valobra A. Feminización y profesionalización de la enfermería (19401955). En: Biernat C, Cerdá JM, Ramacciotti K, directores. La salud pública y la enfermería en la Argentina. Bernal: Universidad Nacional de Quilmes; 2015. p. 287-314.

34. Ramacciotti K. La Fundación Rockefeller y la División Internacional de Salud en el Río de la Plata y la Región Andina: ideas, concreciones y obstáculos (1941-1949). Redes [internet]. 2017;23(45):97-121. Disponible en: http://iec.unq.edu.ar/index.php/es/publicaciones/revista-redes/numeros-anteriores/item/268-redes-45

35. Testa D. La enfermería entre la empiria y la ciencia: el método Kenny. En: Ramacciotti K, directora. Historias de la enfermería en Argentina: pasado y presente de una profesión [internet]. Buenos Aires: Edunpaz; 2020. p. 217-41. Disponible en https://edunpaz.unpaz. edu.ar/OMP/index.php/edunpaz/catalog/download/49/60/187-1?inline=1

36. Testa D. Poliomielitis, rehabilitación y los “etcétera” del cuidado: visitadoras, nurses y voluntarias. Avances del Cesor [internet]. 2016;8(15):157-79. Disponible en: http://web2. rosario-conicet.gov.ar/ojs/index.php/AvancesCesor/index

37. Healey M. El peronismo entre las ruinas: el terremoto y la reconstrucción de San Juan. Buenos Aires: Siglo XXI; 2012.

38. Raffa C. Políticas sanitarias y arquitectura de Estado en Mendoza: el Gran Policlínico Central (1938-1943). Estudios Sociales del Estado. 2020;6(11). https://doi.org/10.35305/ ese.v6i11.207 
39. Pamuk O. Lo que las grandes novelas sobre pandemias nos enseñan. La Nación [internet]; 2020 may 16. Disponible en: https://www.lanacion.com.ar/opinion/lo-que-las-grandes-novelas-sobre-pandemias-nos-ensenanlecturasbiografia-nid2365414

40. Healey M. La trama política de un desastre natural; el terremoto y la reconstrucción de San Juan. Entrepasados. 2002;XI(22):49-66.

41. Ramacciotti K, Valobra A. “Con el descanso del viento”: Margarita Basomba y la enfermería platense. En: Ramacciotti K, editora. Historias de la enfermería en Argentina: pasado y presente de una profesión [internet]. Buenos Aires: Edunpaz; 2020. p. 242-73. Disponible en: https://edunpaz.unpaz.edu.ar/OMP/index.php/edunpaz/catalog/download/49/60/187-1 ?inline=1

42. Castillo H. Quién es quién en La Plata: Margarita Basomba "En toda enfermera hay siempre una Florence Nightingale”. El Día, 3 de febrero de 1999.

43. Di Liscia MS, Álvarez A. Ciudades atormentadas: catástrofes urbanas y atención humanitaria (Cruz Roja Argentina, 1864-1930). Resgate. Rev Interdiscip Cult. 2019;27(2):153-74. https://doi.org/10.20396/resgate.v27i2.8656665

44. Ramacciotti K, Valobra A. Profesión, vocación y lealtad en la enfermería peronista. En: Barry C, Ramacciotti K, Valobra A, editoras. La Fundación Eva Perón y las mujeres en Buenos Aires: entre la provocación y la inclusión. Buenos Aires: Biblos; 2008.

45. Resolución Ministerial 195 del 26 de julio de 1946, Argentina, Secretaría de Salud Pública, Fondo Ministerio de Salud, INIHEP, folio 146.

46. Ramacciotti K, Valobra A. El dilema Nightingale: controversias sobre la profesionalización de la enfermería en Argentina 1949-1967. Dynamis. 2017;3(87):367-87. https://doi. org/10.4321/S0211-95362017000200006

47. Martin H, Illbele F. Los héroes que hemos perdido [internet]. Infobae; 2020. Disponible en: https://especiales.infobae.com/heroes-coronavirus/index.html?fbclid=IwAR07_ O7NN_LFpflfM4O4SSWgrMBfZq84y1QTJB_QFgoslRU_WWPU6NOJwBY

48. América TV. Héroes invisibles [video de YouTube]; 2020 sep 14. Disponible en: https:// www.youtube.com/watch?v=8Jwo9Rpi4_w\&ab_channel=Am\%C3\%A9ricaTV

49. Fiquepron M. Morir en las grandes pestes: las epidemias de cólera y fiebre amarilla en la Buenos Aires del siglo xix. Buenos Aires: Sudamericana; 2020. p. 61. 